\title{
A SILVICULTURA NO MUNICÍPIO DE ROSÁRIO DO SUL: UM ESTUDO DE CASO NO BIOMA PAMPA SUL-RIOGRANDENSE
}

\author{
FORESTRY IN THE MUNICIPALITY OF ROSÁRIO DO SUL: A CASE STUDY IN THE PAMPA SUL-RIOGRANDENSE BIOME
}

\section{RESUMO}

O avanço da silvicultura no bioma Pampa desenvolveu-se como uma estratégia política de estado neoliberalista, camuflada em uma proposta de desenvolvimento econômico da região da Campanha Gaúcha. Este artigo tem como objetivo apresentar um panorama sobre as atividades silviculturais no município de Rosário do Sul, localizado no sudoeste do Rio Grande do Sul. Para isso, elaborou-se uma caracterização da silvicultura a partir do auxílio de mapas temáticos. A construção dos mapas de uso da terra e as suas respectivas análises ocorreram a partir da utilização de imagens do satélite LANDSAT 5 TM para o ano de 1996 e LANDSAT 8 OLI para 2016. O processo de classificação das imagens realizou-se por meio da utilização do software $\mathrm{ENVI}^{\circledR}{ }^{\circledR}$ 4.8, onde foram coletadas amostras referentes aos corpos d'água, vegetação arbóreo-arbustiva, bancos de areia, campos, lavouras, silvicultura e urbano. Durante os trabalhos de campo observou-se que as áreas onde ocorre o cultivo das espécies exóticas, são utilizadas predominantemente para fins comerciais como a fabricação de celulose, sendo poucos os casos em que são utilizados como "quebra-ventos" e para a proteção do gado das pequenas propriedades. Com base no cenário apresentado, pode-se concluir que diferentemente dos municípios da porção oeste do Rio Grande do Sul, em Rosário do Sul o plantio de eucaliptos ocorreu em áreas onde o uso já era destinado para a agricultura, não havendo a necessidade da apropriação de novas áreas com cobertura vegetal nativa, mantendo assim, os campos utilizados para a pecuária que é uma prática tradicional na área de estudo.

Palavras-chave: Neoliberalismo; Plantio; Desenvolvimento Econômico; Uso da Terra; Quebra-ventos.

\section{ABSTRACT}

The advance of forestry in the Pampa biome has developed as a state political strategy neoliberalist, camouflaged in a proposal of economic development of the region of the Campanha Gaúcha. This article aims to present an overview of silvicultural activities in the municipality of Rosário do Suk, located in the southwest of Rio Grande do Sul. For this, a characterization of the forestry through thematic maps was elaborated. The construction of land use maps and their respective analyzes occurred from the use of LANDSAT 5 TM satellite images for the year of 1996 and LANDSAT 8 OLI for 2016. The image classification process was carried out using the software ENVI ${ }^{\circledR} 4.8$, where samples were collected referring to water bodies, arboreal-shrub vegetation, sand banks, fields, crops, forestry and urban. During the field works it was observed that the areas where are the cultivation of exotic species, are used predominantly for commercial purposes such as the manufacture of cellulose, being few cases that are being used as "windbreaks" and for the protection of livestock small properties. Based on the presented scenario, can be concluded that unlike municipalities Rio Grande do Sul, in Rosario do Sul, eucalyptus plantations occurred in areas where was destined for agriculture, and there was no need for the appropriation of new areas with native vegetal cover, thus maintaining the fields used for livestock which is a traditional practice in the area of study.

Keywords: Neoliberalism, planting, economic development, land use, windbreak.

\author{
Daniélli Flores Dias ${ }^{a}$ \\ Jonatas Giovani Silva Aimon ${ }^{\text {a }}$ \\ Rodrigo Corrêa Pontes ${ }^{\text {a }}$ \\ ${ }^{\text {a }}$ Universidade Federal de Santa Maria \\ (UFSM), Santa Maria, RS, Brasil
}

DOI: 10.12957/geouerj.2020.38045

Correpondência: daniellidias08@gmail.com

Recebido em: 29 out. 2018

Revisado em: 3 maio 2019

Aceito em: 28 abr.2020 


\section{INTRODUÇÃO}

A presença do capital internacional em diversos países do mundo permitiu uma intensa e veloz modernização e tecnificação das atividades relacionadas à agricultura e à silvicultura, onde o Bioma Pampa e seus elementos naturais tornaram-se ameaçados pelo ingresso de tais alternativas e práticas (SUERTEGARAY; SILVA, 2009).

Dentro de um contexto capitalista e expansionista, esse processo permitiu o ingresso das ações antrópicas em inúmeros espaços que antes não eram visados para atividades agrícolas, onde espaços naturais têm sido impactados e convertidos em extensas áreas monoculturais, com a finalidade de reproduzir o capital (ACHKAR; DOMINGUEZ; DÍAS; PESCE, 2011). A conversão de áreas devido o aumento da demanda comercial e o desejo de rápida obtenção de lucros apresentam-se a uma ameaça para os recursos naturais, sendo que novas áreas são almejadas para o estabelecimento e expansão de tais atividades.

Conforme Netto (2017), a região do Pampa Gaúcho vem sendo utilizada pelo modelo produtivista como uma fronteira agrícola a ser desbravada, onde desenvolve-se um padrão de agricultura vinculado a uma estrutura de produção em massa e tecnológica, aumentando as áreas naturais reconvertidas para extensas lavouras de diversas monoculturas. Tal processo de reconversão proporciona a perda de potencial produtivo, reduzindo as áreas de campos nativos causando prejuízos irreversíveis a biodiversidade, recursos hídricos e solos (SUERTEGARAY; SILVA, 2009). Também, de acordo com Netto (2017) apresenta-se como uma atividade agrícola dependente das especulações e oscilações de preços do mercado internacional e vulnerável aos riscos climáticos.

Anteriormente, Develey; Setubal; Dias; Bencke (2009) definiram que as grandes ameaças do bioma Pampa, além do aumento das áreas de cultivo de arroz e soja, têm-se a expansão da silvicultura, representada em grandes áreas de monocultivo de espécies exóticas em porções de campos nativos. Dados demonstram que os avanços da agricultura e silvicultura convertem campos naturais em áreas de diversidade biológica, sem prévio planejamento e monitoramento das intervenções.

O avanço da silvicultura neste bioma desenvolveu-se como uma estratégia política de estado neoliberalista, camuflada em uma proposta de crescimento econômico da região da Campanha Gaúcha. Desde o ano de 1996, o Governo gaúcho decidiu promover a silvicultura como forma de crescimento econômico em regiões interioranas da metade sul, tradicionalmente caracterizada pelo grande latifúndio e por carência de novos investimentos. O objetivo era transformar a economia pastoril da metade sul do Rio Grande do Sul, em uma região de produção de madeira e celulose para o mercado internacional (SUERTEGARAY e SILVA, 2009).

Políticas públicas para o início das atividades foram criadas, como programas e incentivos financeiros para o estabelecimento de plantios, especialmente para produtores da metade sul. Empresas estrangeiras 
como Aracruz Celulose, Stora Enso e a nacional Votorantim, foram atraídas por incentivos fiscais e pelas condições físicas propícias ao cultivo de espécies, onde passaram a investir massivamente alterando o cenário do campo (CHOMENKO, 2017).

Dessa forma, criou-se um forte polo florestal, onde diversos questionamentos começaram a ser levantados por parte de investidores, que acreditavam estar gerando empregos e inserindo pequenos e médios produtores na dinâmica capitalista e também por ambientalistas, que já contestavam os benefícios dessas atividades perante a biodiversidade e os ecossistemas (PICOLLI e SCHNADELBACH, 2007).

Com o discurso do desenvolvimento econômico na metade sul do Estado, as empresas citadas instalaram-se na porção sudoeste, forçando os proprietários a comercializarem suas terras a preços muito baixos, causando problemas ambientais, econômicos e sociais. De acordo com Pereira (2010), a promessa de um rápido retorno financeiro e a pressão das empresas fez com que muitos proprietários dessas áreas cedessem as ofertas do capital estrangeiro.

A silvicultura teve um aumento significativo nas áreas de cultivo após o ano de 2004, quando projetos foram anunciados para a implantação de fabricas de celulose. Desde então, dados do ano de 2013 confirmam que o avanço desta atividade foi de 200 mil hectares de efetivo plantio sobre o bioma Pampa (FUNDAÇÃO ESTADUAL DE PROTEÇÃO AMBIENTAL, 2013).

A exploração de madeira dessa área requer muita cautela e laudos minuciosos, já que a área apresenta ecossistema frágil. Estudos demonstram que existem mais de 2.200 espécies campestres constituindo um patrimônio genético notável até então pouco conhecido e com grande endemismo (MARCHIORI e ALVES, 2007).

O zoneamento ambiental é uma exigência legal na escala federal e estadual. Para o Rio Grande do Sul, está previsto no Código Estadual de Meio Ambiente, através da Lei no 11.520 de 03 de agosto de 2000 . Vergonhosamente, os diversos interessados na expansão desta atividade conduziram de diversas formas esta política, até torná-la conveniente aos mesmos. Apesar disso, em algumas porções do sudoeste do Rio Grande do Sul, o zoneamento ambiental definiu quatro unidades de paisagem como áreas de média e alta restrição. Mesmo assim, a proposta da silvicultura como alternativa retificadora da economia, contrariou os princípios do ambientalismo através da apropriação indevida de recursos naturais como água, solo e vegetação (SUERTEGARAY e SILVA, 2009).

Assim, este artigo objetiva apresentar um panorama sobre as atividades silviculturais no município de Rosário do Sul, localizado na porção sudoeste do Rio Grande do Sul, retratando as possíveis consequências causadas desde a sua implantação sobre o bioma Pampa. 


\section{MATERIAIS E MÉTODOS}

Os materiais utilizados para a estruturação do banco de dados foram: Base Cartográfica Vetorial Contínua do Rio Grande do Sul desenvolvida por Hasenack e Weber (2010) com escala 1:50.000 e utilizada para identificar a rede hidrográfica do município; Malha Digital do IBGE (2010) que serviu para a demarcação do limite municipal de Rosário do Sul; Imagens de satélite da Série LANDSAT 5 e 8 obtidas junto ao United States Geological Survey que foram utilizadas para a elaboração dos mapas de uso da terra referente aos anos de 1996, 2016 e o mapa da silvicultura; softwares ArcGIS $^{\circ}$ 10.1, Google Earth Pro e ENVI ${ }^{\circledR} 4.8$ que foram utilizados para a geração do banco de dados georreferenciado e a respectiva elaboração dos mapas de localização, uso da terra e silvicultura.

$\mathrm{Na}$ interface do usuário do software $\operatorname{ArcGIS}^{\circ} 10.1$ foi criado um Geodatabase onde foi definido como Sistema de Referência o Sistema Universal Transversa de Mercator (UTM), com Datum SIRGAS 2000, Fuso 21, Hemisfério Sul.

Para a definição do uso da terra referente aos anos de 1996 e 2016, utilizou-se as imagens do satélite LANSAT 5 TM (1996) e 8 OLI (2016), com órbita ponto 223/81 e 224/81, adquiridas através do website: http://www.earthexplorer.usgs.gov. (USGS, 2016).

O processo de classificação dessas imagens ocorreu dentro do ambiente do software $\mathrm{ENVI}^{\circ} 4.8$ onde foram coletadas amostras referentes aos corpos d'água, vegetação arbóreo-arbustiva, bancos de areia, campos, lavouras, silvicultura e área urbana.

Após a coleta das amostras e conferência da acurácia das mesmas, os arquivos foram exportados para o software ArcGIS 10.1 onde ocorreu a transformação de matriz para vetor, com a utilização da ferramenta Raster to Polygon. Posteriormente, pôde-se refazer a edição vetorial das classes de uso da terra, através de uma revisão das amostras classificadas erroneamente. Na classificação do ano de 1996, a classe dos solos expostos preparados para as plantações foram agrupadas as lavouras, e as sombras foram inseridas na classe de vegetação arbóreo-arbustiva. Já no ano de 2016, a classe dos solos expostos após a colheita foram anexados as lavouras. Por sua vez, a classe da área urbana (denominado "urbano" nos mapas finais), foi vetorizada manualmente, em decorrência da confusão na classificação automatizada com a classe dos bancos de areia. Após a vetorização manual, atribuiu-se um novo código identificador para a classe do urbano e as áreas das demais classe de uso foram novamente calculadas.

Para a caracterização da silvicultura, elaborou-se um mapa ilustrando em quais áreas ela ocorreu e como se dá a distribuição dessa monocultura no município de Rosário do Sul. 
Os trabalhos de campo, por sua vez, foram realizados de forma investigativa, tendo como objetivo identificar o substrato litológico da área, os tipos de relevo e solos, as formações vegetais presentes e a configuração do uso da terra. Assim, destaca-se que estes foram imprescindíveis para entender as principais modificações da paisagem. No decorrer dessas atividades realizou-se o levantamento fotográfico que serviu para a caracterização física da área de estudo. Além disso, foi utilizado um Sistema de Posicionamento Global (GPS Garmin Etrex) para obter a localização dos pontos de controle obtidos durante os trabalhos de campo.

\section{APRESENTAÇÃO DA ÁREA DE ESTUDO}

O município de Rosário do Sul (Figura 1), localiza-se na porção sudoeste do Rio Grande do Sul, entre as coordenadas geográficas de 3000'55" e 3045'01" (latitude sul) e 5543'15" e 5437'19” (longitude oeste). Em um contexto mais amplo, insere-se na Mesorregião Sudoeste Rio-Grandense e na Microrregião da Campanha Central.

Figura 1. Localização da área de estudo. Fonte: Elaborado pelos autores (2018).




Conforme dados do Instituto Brasileiro de Geografia e Estatística (IBGE, 2010), o município possui uma área de 4.369,32 km², população total de 40.773 habitantes e densidade demográfica de $9,09 \mathrm{hab} / \mathrm{km}^{2}$. Seus limites territoriais são a noroeste com Alegrete, ao norte com Cacequi, ao sul com Dom Pedrito, a oeste com Quaraí, a sudoeste com Santana do Livramento e a leste com São Gabriel.

\section{CARACTERIZAÇÃO DO AMBIENTE NATURAL}

Ao realizar um zoneamento geoambiental no município de Rosário do Sul, Dias (2017) definiu que a área de estudo possui suas terras drenadas por dois sistemas hidrográficos: a sub-bacia do rio Santa Maria banhando a porção leste; e a sub-bacia rio Ibirapuitã ocupando a porção oeste. De forma geral, Rosário do Sul insere-se na região hidrográfica do rio Uruguai e na bacia hidrográfica do rio Ibicuí.

Geomorfologicamente, Rosário do Sul encontra-se na zona de transição entre a Depressão Periférica Sul-rio-grandense e os Planaltos e Chapadas da Bacia do Paraná (Ross, 1996). Assim, a área de estudo tem como menor cota altimétrica 83 metros, localizado junto a foz do rio Santa Maria e a maior cota de 363 metros juntos a Serra do Caverá, resultando em uma amplitude altimétrica de 280 metros.

Desta forma, destaca-se que a área de estudo apresenta uma diversidade de formas de relevo, classificadas como áreas planas próximas a rede hidrográfica, colinas, associação de morros e morrotes, morros e morrotes isolados da Serra do Caverá (DIAS, 2017).

O município apresenta substrato litológico composto por rochas sedimentares e vulcânicas da Bacia do Paraná e os depósitos recentes do rio Santa Maria. Assim, conforme a classificação estabelecida pela Companhia de Pesquisa e Recursos Minerais (CPRM, 2007), a área de estudo é composta pelas seguintes litologias: depósitos recentes, rochas vulcânicas (Fácies Alegrete e Gramado) e rochas sedimentares (Formações Botucatu, Guará, Piramboia, Rio do Rasto, Sanga do Cabral e subgrupo Estrada Nova).

A ampla variedade das litologias e das formas de relevo são responsáveis pelos distintos solos encontrados no município (Figura 2). Com base nisso e nas discussões de Streck, Kämpf, Dalmolin, Klant (2002) são encontrados solos profundos como argissolos, chernossolos, luvissolos e vertissolos, associados as colinas levemente onduladas e onduladas com substrato litológico composto por arenito pouco cimentado, que permitem o desenvolvimento de perfis de solo espessos; solos rasos do tipo neossolos que apresentam horizonte mineral incipiente ou inexistente, que contém apenas um horizonte orgânico; solos hidromórficos como gleissolos e planossolos com presença significativa de matéria orgânica. 
Figura 2. Litologias e formas de relevo na área de estudo: (A) Morros e morrotes da Serra do Caverá; (B) Mata ciliar do rio Ibirapuitã; (C) Neossolos litólicos; (D) Frailea castanea, espécie endêmica e ameaçada de extinção; (E) Mimosa sp. (Fabaceae); (F) Butia lallemantii (Arecaceae) em afloramento rochoso. Fonte: Rodrigo Pontes, Jan-Jun (2017).

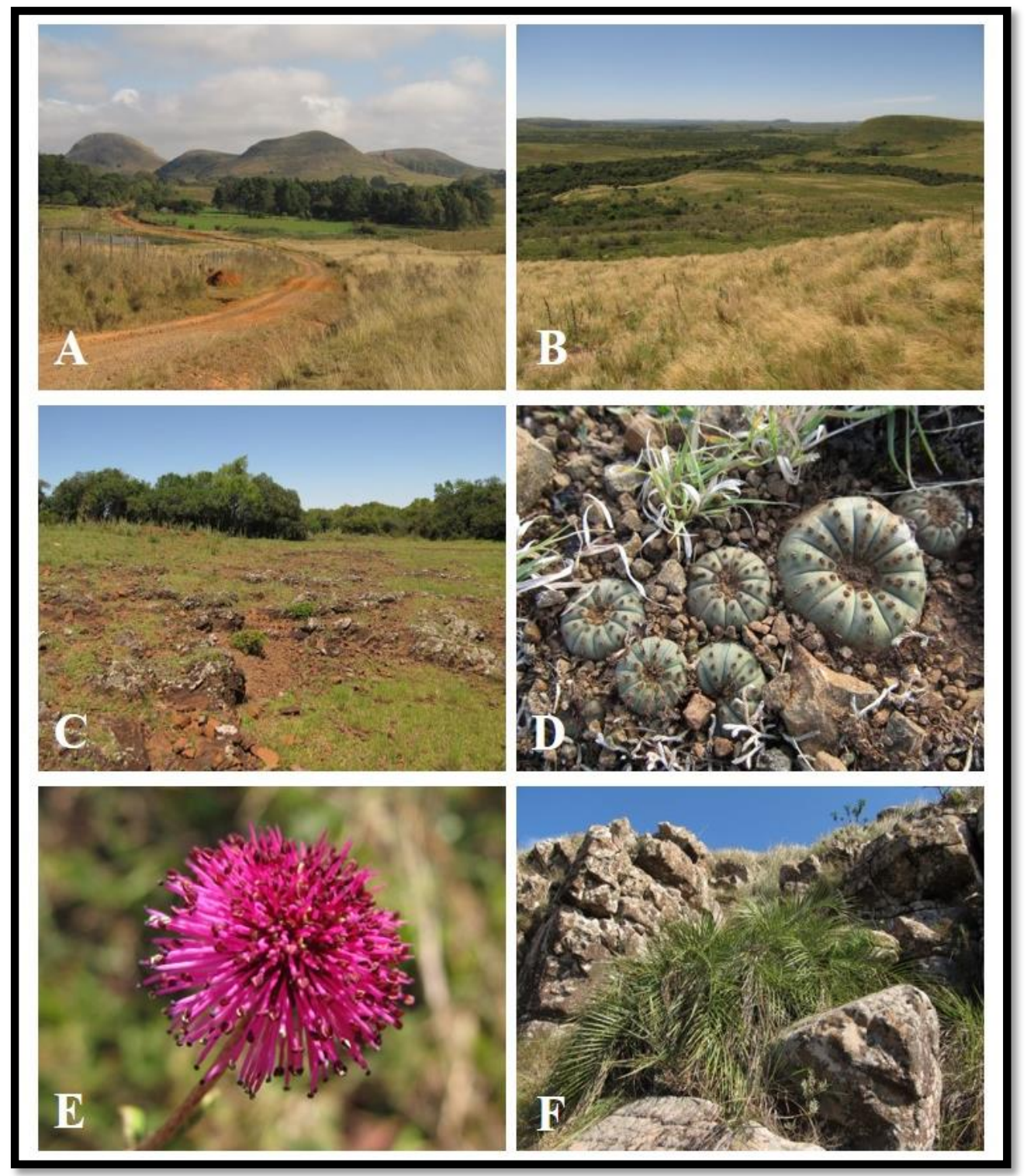

Com relação aos aspectos bióticos (Figura 3), o município de Rosário do Sul está inserido em uma área de campos, com uma vegetação predominantemente campestre (Lindmann, 1906; Rambo, 1956). Conforme o IBGE (2010), o referido município encontra-se no bioma Pampa, com extensão de $176.496 \mathrm{~km}^{2}$ que se estende por $63 \%$ do território gaúcho. Rambo (1956) e Marchiori (2002), definem que a vegetação do Rio Grande do Sul ocorre em um período transitório induzido pelos padrões climáticos firmados entre os períodos do Pleistoceno e do Holoceno.

Os referidos autores juntamente com Cabrera e Willinck (1973), consideram que a paisagem do Pampa apresenta indícios de períodos de clima seco, perceptíveis nas características morfofisiológicas de elementos florísticos e mostramse aparentemente inadequadas às condições climáticas atuais. Dessa forma, esses elementos são como testemunhos paleoclimáticos das restrições submetidas em tempos pretéritos. 
Conforme Boldrini (2010), existem nove tipologias de campos, caracterizadas pelos seus aspectos físicos e ecológicos como geomorfologia, táxons, ameaças e graus de conservação. Três dessas fitofisionomias encontram-se na área de estudo: Campos de Areais, Campos da Depressão e Campos de Solos Rasos.

Os Campos de Areais encontram-se entre a Depressão Periférica Sul-Riograndense e Planaltos e Chapadas da Bacia do Paraná, em terrenos planos a ondulados associados a afloramentos rochosos, apresentando cerca de $45 \%$ da área natural, com elementos arbóreos distribuídos em florestas de galeria e capões de mato (BOLDRINI; FERREIRA; ANDRADE; SCHNEIDER; SETUBAL; TREVISAN; FREITAS, 2010; CARNEIRO; SINGER; RAMOS; NILSON, 2016).

A segunda formação corresponde a Depressão Periférica com topografia plana a suavemente ondulada, apresentando morrotes e morros testemunhos sedimentares capeados por rochas vulcânicas. Conforme Carneiro, Singer, Ramos, Nilson (2016), campos com ou sem florestas de galeria são predominantes, com a ocorrência da Floresta Estacional e ainda nesta área, ocorrem banhados e extensas várzeas, com apenas $35 \%$ de sua vegetação natural.

Nos Campos de Solos Rasos encontram-se Planaltos e Chapadas da Bacia do Paraná, que compreendem a fisionomia típica dos campos do Pampa Sul-riograndense. Apresenta relevo plano, onde a vegetação é caracterizada por campos sem floresta de galeria, consistindo em cerca de 70\% da superfície de áreas naturais (BOLDRINI; FERREIRA; ANDRADE; SCHNEIDER; SETUBAL; TREVISAN; FREITAS, 2010; CARNEIRO; SINGER; RAMOS; NILSON, 2016).

Os campos são a formação vegetal mais abundante, presente em solos arenosos, em processo de arenização e colinas de arenito e rochas vulcânicas. Devido aos solos rasos e rochosos, as colinas de arenito são locais onde não há uma interferência antrópica excessiva e geralmente apresentam espécies xerófitas e suculentas, algumas endêmicas e ameaçadas de extinção (MARCHIORI, 2004). A vegetação das cornijas e morrotes de arenitos apresentam espécies suculentas de caráter xerófito, sempre associadas a patamares rochosos com substrato arenoso. No entorno desses morrotes, em vertentes úmidas e entre os blocos de rochas, desenvolve-se uma vegetação de caráter arbóreo em seu topo, encontram-se herbáceas de pequeno porte (ALVES; MARCHIORI; ROBAINA, 2009).

As matas ciliares são encontradas ao longo da rede hidrográfica, com composição variada de elementos e dimensões. O uso e a ocupação da terra nessas áreas campestres estão diretamente condicionados por aspectos geomorfológicos e litológicos, que limitam o estabelecimento e impacto de práticas antrópicas. Os impactos presentes nos Campos dos Areais estão associados as atividades de pecuária, orizicultura, cultura de trigo, soja e silvicultura (SUERTEGARAY e SILVA, 2009).

Nos Campos da Depressão Central, devido à presença de banhados e extensas várzeas, a pressão antrópica é perceptível nas áreas mencionadas anteriormente, com exceção da cultura de trigo. Por fim, os Campos de Solos Rasos apresentam áreas ocupadas pela silvicultura, mas ainda são pouco significativas devido à presença dos neossolos litólicos (ALVES; MARCHIORI; ROBAINA, 2009) 
Ainda, Bencke (2009) destaca que cerca de 40 espécies de animais que habitam campos estão ameaçadas de extinção no Pampa gaúcho, como o veado-campeiro, lobo-guará, gato-palheiro, além de algumas espécies de aves.

Figura 3. Aspectos arquitetônicos, bióticos e econômicos na área de estudo: (A) Antigo mausoléu em estilo espanhol; (B) Morros e morrotes da Serra do Caverá; (C) Oxypetatum coerulem (Apocynaceae), no bioma Pampa; (D) Silvicultura presente em Rosário do Sul;

(E) Criação de cavalos, atividade tradicional fortemente vinculada a imagem de gaúcho; (F) Cornija com a presença de Cereus hildmannianus (Cactaceae). Fonte: Rodrigo Pontes, Jan-Jun (2017).

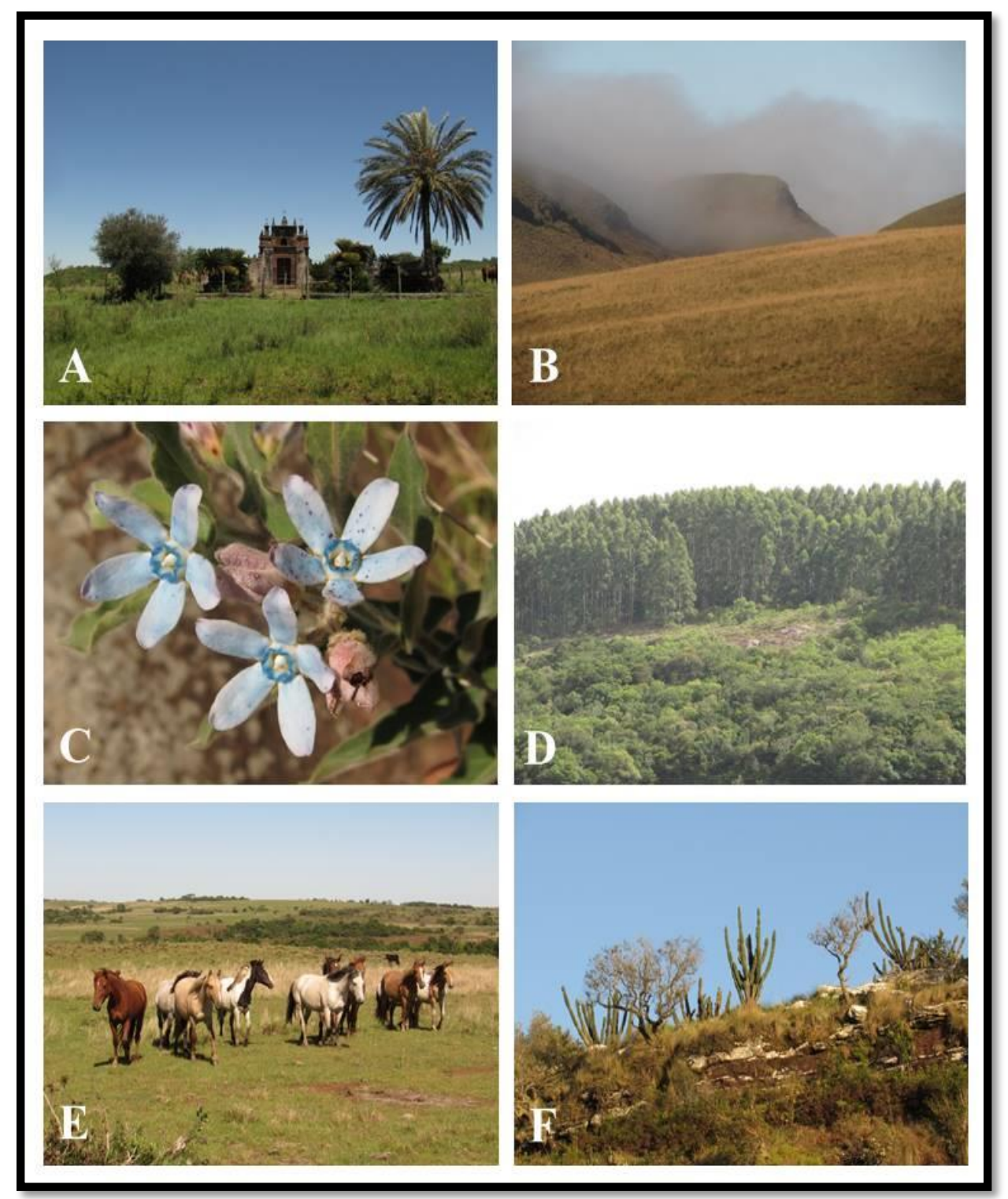

\section{O USO DA TERRA E A DINÂMICA DA SILVICULTURA}

Assim como em toda a porção oeste do Rio Grande do Sul, conforme Suertegaray e Silva (2009), as atividades de uso da terra do município de Rosário do Sul, estão historicamente baseadas na pecuária, agricultura e tem a silvicultura como um importante papel no desenvolvimento econômico. 
Para o município de Rosário do Sul, os usos mapeados e caracterizados foram: corpos d'água que é composto pela rede hidrográfica e pelos açudes; vegetação arbóreo-arbustiva que são áreas de cobertura vegetal de características naturais, compostas pelas matas ciliares e a vegetação em áreas escarpadas; bancos de areia que são sedimentos que se depositam nas margens dos rios, campos que são áreas com cultivos de pastagens onde ocorre a prática da pecuária extensiva; lavouras que correspondem as áreas agrícolas onde ocorre principalmente o cultivo de soja e arroz; silvicultura que são áreas onde ocorreu a implantação de espécies exóticas de eucaliptos; urbano que corresponde a área urbana de Rosário do Sul (DIAS, 2017).

Na classificação realizada para 1996 (Figura 4), a classe dos campos representa o tipo de uso mais expressivo, conferindo $65,77 \%$ do total da área de estudo, que são utilizados principalmente para a prática da pecuária de bovinos e ovinos.

Figura 4. Distribuição das classes de uso da terra no município de Rosário do Sul no ano de 1996.

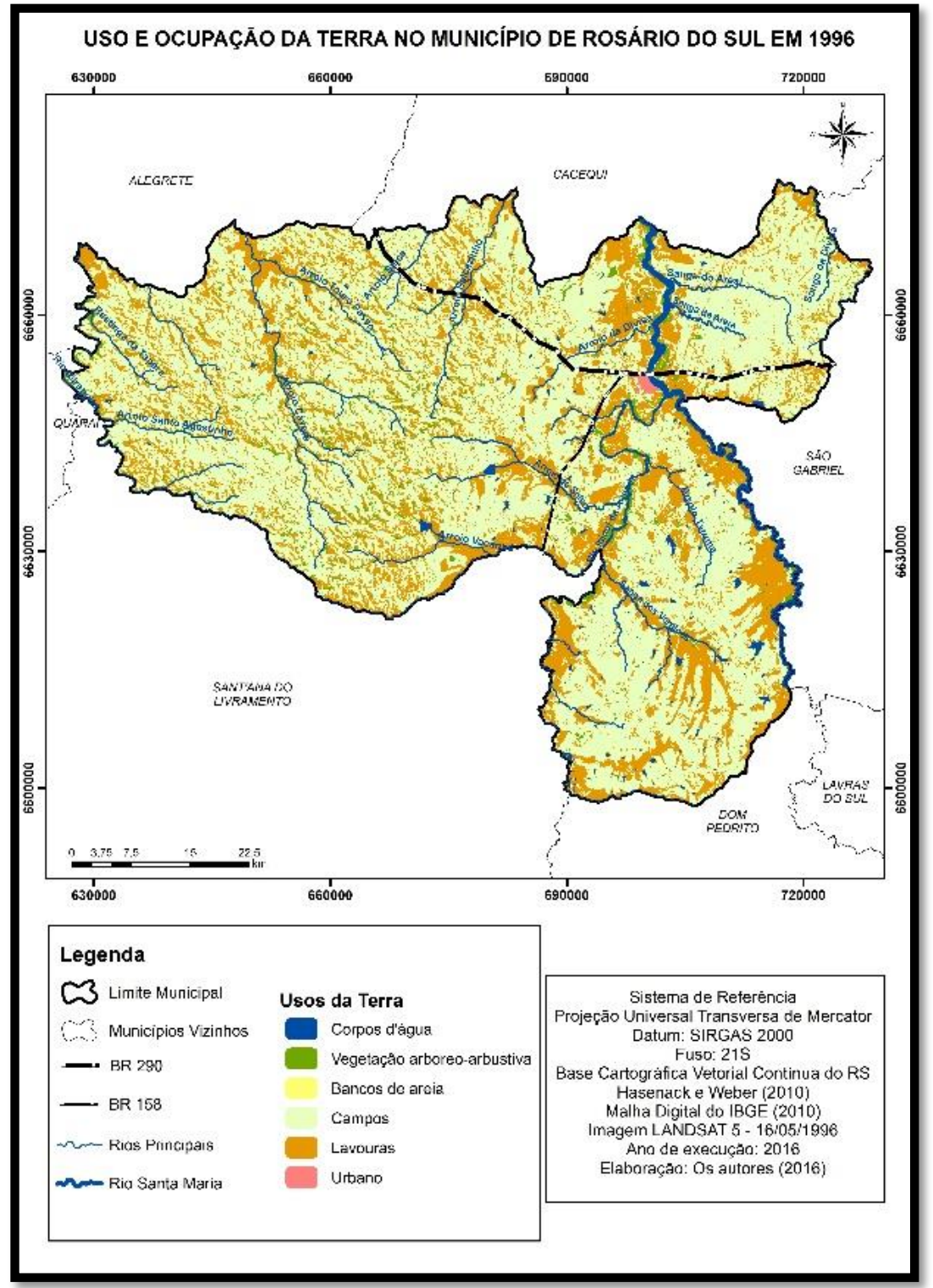


A classe dos corpos d'água corresponde a 0,81\% e é composta pelos açudes que são utilizados para a irrigação e dessedentação dos animais e os segmentos de canais da rede hidrográfica com largura igual ou superior a 30 metros, visíveis em razão da resolução espacial da imagem utilizada para a classificação.

A classe da vegetação arbóreo-arbustiva representa $4,22 \%$ e é formada predominantemente pela vegetação campestre originária do Bioma Pampa, além da vegetação arbórea que se localiza nas margens dos rios e arroios (matas ciliares ou de galeria), e nas áreas íngremes de morros e morrotes e cornijas da Serra do Caverá.

Considerada a classe de uso menos expressiva, os bancos de areia representam 0,08\% e depositam-se nas margens dos dois principais rios do município: Santa Maria e Ibicuí da Armada.

A classe de uso das lavouras representa $28,97 \%$ do município de Rosário do Sul e nessas áreas, ocorre o cultivo do arroz e da soja, além de outras culturas como o milho, feijão e hortifruti.

Em 1996, a classe da silvicultura em Rosário do Sul era inexistente. Isso é explicado em razão de que o plantio do eucaliptos na porção oeste e sudoeste do Rio Grande do Sul teve início em 1996 no município de Cacequi. Foi somente no início dos anos 2000 que deu-se o processo de plantação de eucaliptos em grandes áreas no município de Rosário do Sul.

Por fim, a classe de uso denominada de urbano é representada pela área urbana do município de Rosário do Sul, correspondendo a 0,15\%. Vale salientar que nos municípios da porção oeste do Rio Grande do Sul, a extensão territorial é muito significativa, porém com áreas urbanas pouco expressivas.

Na classificação realizada no ano de 2016 (Figura 5), a classe dos campos representa 66,64\% e, assim como em 1996, configura a classe de uso mais expressiva. Predominantemente, os campos são utilizados para a pecuária com a criação de bovinos e ovinos. De acordo com dados da Produção de Pecuária Municipal (IBGE, 2015), o município de Rosário do Sul conta com um rebanho de aproximadamente de 345.174 cabeças de gado e 153.136 ovinos, além de outras criações como equinos, bubalinos e caprinos. 
Figura 5. Distribuição das classes de uso da terra no município de Rosário do Sul no ano de 2016.

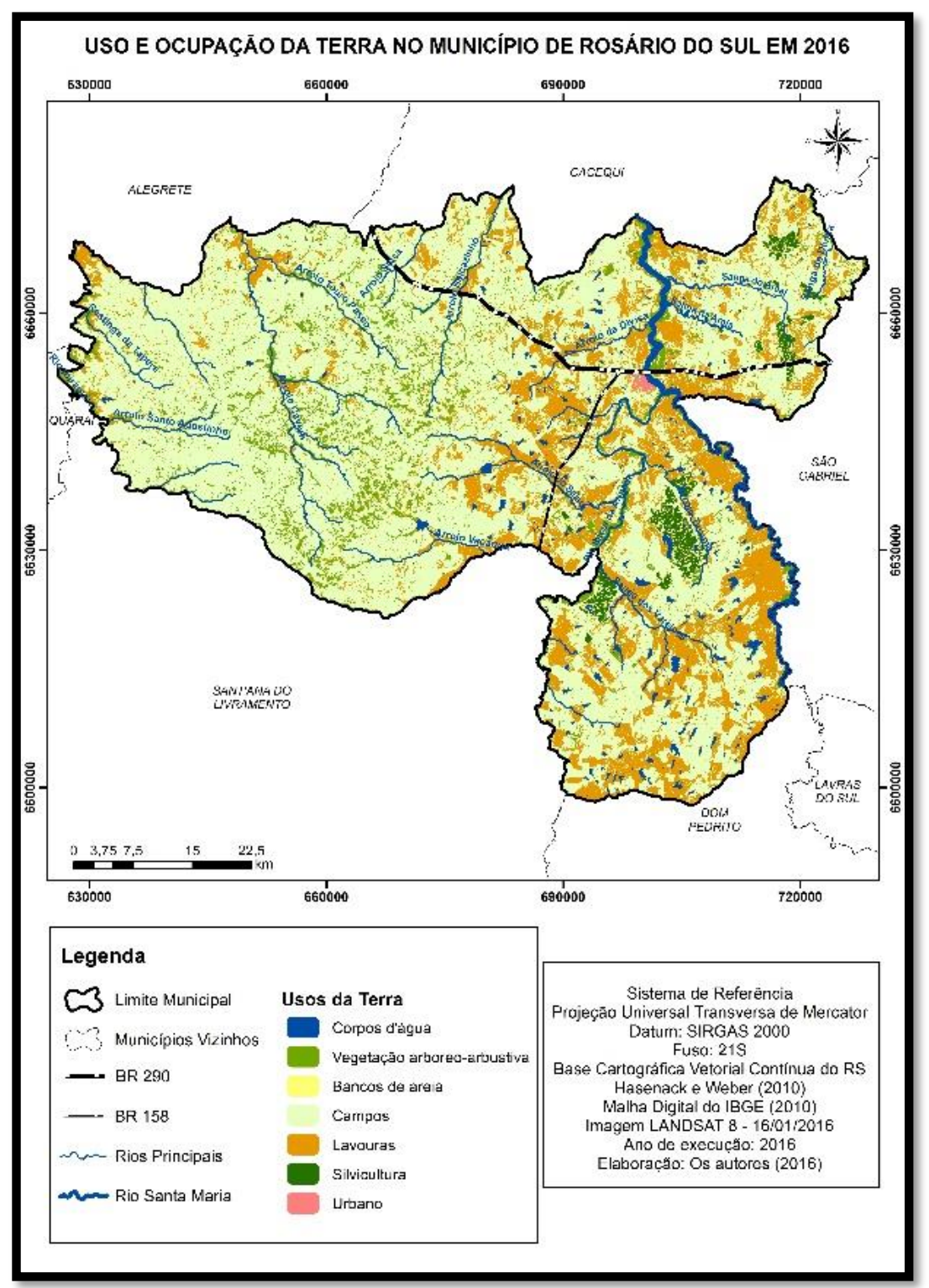

Os corpos d'água correspondem a 1,60\% da área de estudo e, assim como em 1996, caracteriza-se por apresentar a rede hidrográfica, além das represas e os açudes utilizados para a irrigação e para a dessedentação dos animais.

Em 2016, a classe de uso da vegetação arbóreo-arbustiva representa 7,51\% e assim como a classificação anterior, é composta por vegetação campestre, arbórea nas margens dos rios e arroios, além das áreas de encostas da Serra do Caverá e, que nessa classificação se fizeram bastante presentes.

A classe dos bancos de areia representa $0,27 \%$ e assim como na classificação anterior, esses depósitos ocorrem principalmente nas margens dos rios Santa Maria e Ibicuí da Armada. 
Já a classe de uso das lavouras, no ano de 2016, representou 22,46\% da área de estudo. Assim como na classificação anterior, nessas áreas ocorre o cultivo de arroz (principalmente nas margens do rio Santa Maria), soja, milho, feijão e hortifruti.

Diferentemente do ano de 1996, em 2016 a classe de uso da silvicultura já se faz presente no município, representando $1,37 \%$ do total da área de estudo. Nessas áreas ocorre o predomínio do eucalipto (Eucalyptus $s p)$ e, conforme foi observado durante os trabalhos de campos, as áreas com cultivo de espécies exóticas são utilizadas preferencialmente para fins comerciais.

Por fim, a classe do urbano segue sendo representada pela área urbana do município de Rosário do Sul, com a mesma área territorial, tendo mudado apenas o crescimento da população total.

Ao comparar o uso da terra entre os anos de 1996 e 2016, é possível observar as principais mudanças e evoluções que ocorreram na paisagem do município. Assim, denota-se que as principais evoluções relacionamse a classe dos bancos de areia, demonstrando que os depósitos de barra de meandro estão intensificando e acelerando os impactos ambientais na área.

A vegetação arbóreo-arbustiva apresentou um considerável aumento de $43,78 \%$, o que indica que atualmente as áreas de morros e morrotes vem sendo mais preservados. Os corpos d'água tiveram um aumento de $50 \%$ em relação a 1996 , com a criação de novos açudes na porção sul do município, utilizados para a dessedentação dos animais.

É importante salientar que houve um pequeno aumento das áreas de campos $(1,32 \%)$ e um decréscimo de $22,51 \%$ das lavouras, que foram substituídas pela silvicultura (Figura 6), pois no município de Rosário do Sul, ainda não ocorreu um entrada agressiva dessa monocultura, pois a mesma foi implementada em áreas de lavouras que já estavam sendo exploradas economicamente, não havendo a necessidade de se apropriarem de novas áreas.

Além disso e conforme foi observado nos trabalhos de campo, é possível afirmar que essas áreas com o cultivo de espécies exóticas, são utilizadas predominantemente para fins comerciais com a fabricação de celulose, sendo poucos os casos em que são utilizados como "quebra-ventos" e para a proteção do gado bovino das pequenas propriedades. 
Figura 6. Espacialização da silvicultura na área de estudo.

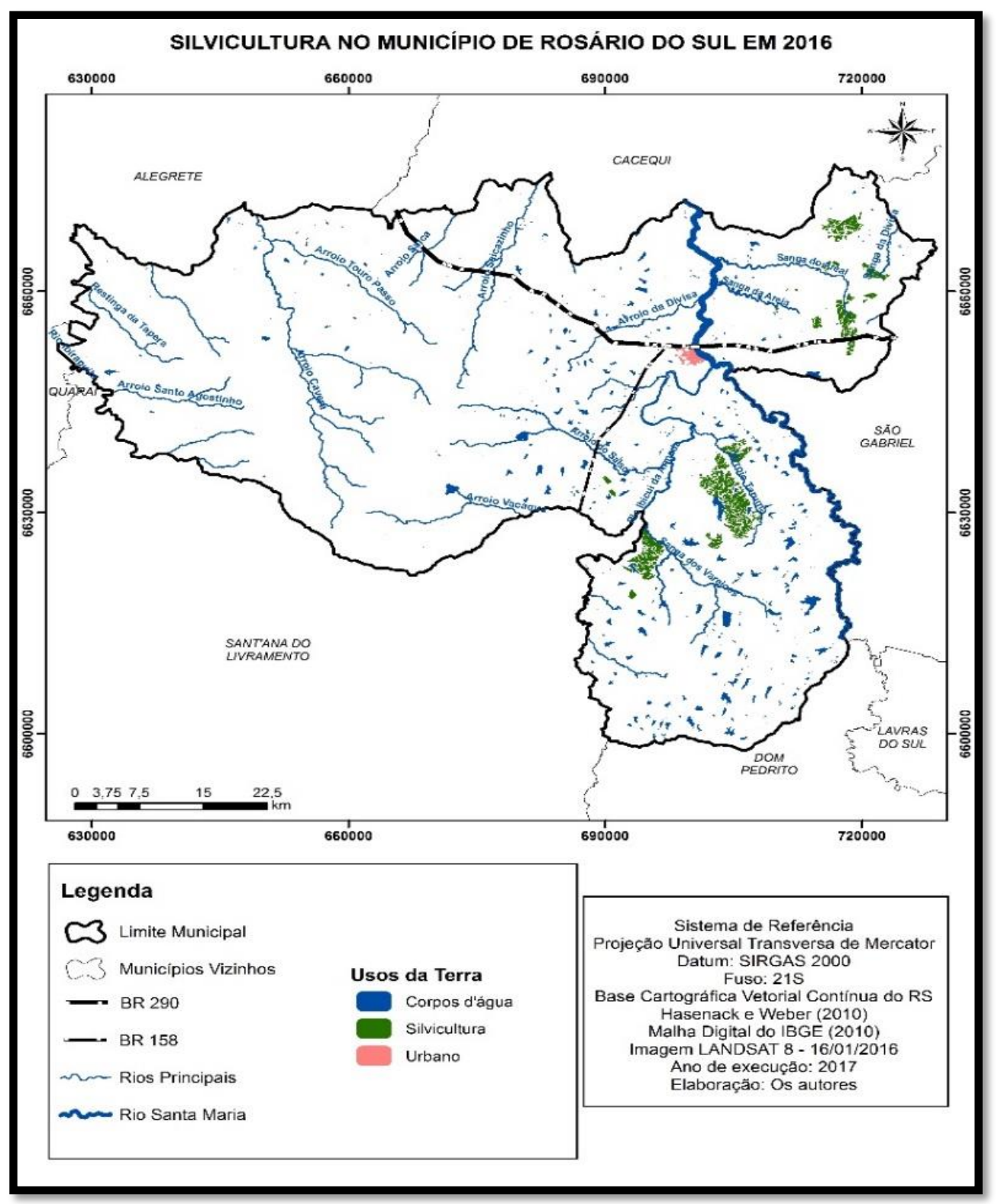

\section{CONCLUSÕES}

Frente ao cenário apresentado, é importante salientar a relação entre os problemas ambientais atuais e os meios de produção, a partir da grande ascensão do agronegócio no Rio Grande do Sul.

Nessa dinâmica atual inserção de novas culturas, entre as novas frentes de expansão, destaca-se a silvicultura, contrastando com as demais já consolidadas, na sua grande maioria como substituição de culturas.

Diferentemente dos municípios da porção oeste do Rio Grande do Sul, em Rosário do Sul, o plantio de eucaliptos ocorreu em áreas onde o uso já era destinado para a agricultura, não havendo assim, a necessidade 
da apropriação de áreas com cobertura vegetal nativa, mantendo assim, os campos destinados para a pecuária que é uma atividade tradicional na área de estudo.

Felizmente, é importante destacar que o processo de estabelecimento da silvicultura foi e continua pequeno, pois a orizicultura e a pecuária são práticas bem consolidadas e tradicionais no município.

Diante da realidade apresentada faz-se necessário nos próximos anos a discussão de novas estratégias para o desenvolvimento socioeconômico, além da consolidação de um zoneamento propondo um melhor ordenamento das fronteiras agrícolas e o manejo de culturas de ciclo longo.

\section{REFERÊNCIAS}

ACHKAR, Marcel; DOMINGUEZ, Ana; DÍAZ, Ismael; PESCE, Fernando. La intensificación del uso agrícola del suelo en el litoral oeste del Uruguay en la última década Pampa n. 07. Suplemento especial temático, 2011.

ALVES, Fabiano da Silva; MARCHIORI, José Newton Cardoso; ROBAINA, Luis Eduardo de Souza. Aspectos fitogeográficos da bacia hidrográfica do Arroio Lajeado Grande, RS - Brasil. 2 - Vegetação campestre. Balduínia, n. 19, p. 01-09, 2009.

BENCKE, Glayson Ariel. Diversidade e conservação da fauna dos Campos do Sul do Brasil. In: PILLAR, Valério de Patta; MÜLLER, Sandra Cristina; CASTILHOS, Zélia Maria de Souza; JACQUES, Aino Victor Ávila. (Orgs.). Campos sulinos - conservação e uso sustentável da biodiversidade. Brasília: Ministério do Meio Ambiente, 2009. 408p. p. 101-121.

BOLDRINI, Ilsi lob; FERREIRA, Pedro Maria de Abreu; ANDRADE, Bianca Ott; SCHNEIDER, Angelo Alberto; SETÚBAL, Robberson Bernal; TREVISAN, Rafael; FREITAS, Elisete Maria de. Bioma Pampa: Diversidade florística e fisionômica. Porto Alegre: Pallotti, 2010.

CABRERA, Ángel Lulio; WILLINK, Abrahan. Biogeografia de América Latina. Washington: Secretaria General de la Organización de los Estados Americanos (OEA), 1973.

CARNEIRO, Andréia Maranhão; SINGER, Rosana Farias; RAMOS, Ricardo Aranha; NILSON, Ari Delmo. Cactos do Rio Grande do Sul. Porto Alegre: Fundação Zoobotânica do Rio Grande do Sul, 2016.

CHOMENKO, Luiza. Pampa: Um Bioma em extinção (2017). Disponível em:

http://www.ihuonline.unisino.br/media/pdf/IHUOnlineEdicao247.pdf. Acesso em: 03 dez. 2017.

COMPANHIA DE PESQUISAS E RECURSOS MINERAIS. Gravataí - SH,22-X-C-V, escala 1:100.000: nota explicativa. Porto Alegre: UFRGS/CPRM, 2007.

DEVELEY, Pedro Ferreira; SETUBAL, Robberson Bernal; DIAS, Rafael Antunes; BENCKE, Glayson Ariel. Conservação das aves e da biodiversidade no bioma Pampa aliada a sistemas de produção animal. Revista Brasileira de Ornitologia, Rio Grande, v. 16, n. 04, p. 308-315, 2009.

DIAS, Daniélli Flores. Zoneamento Geoambiental aplicado ao estudo das potencialidades e suscetibilidades ambientais e de uso e ocupação de Rosário do Sul/RS. 2017.Dissertação (Mestrado em Geografia) - Universidade Federal de Santa Maria, Santa Maria, 2017.

FUNDAÇÃO ESTADUAL DE PROTEÇÃO AMBIENTAL. Banco de dados da silvicultura do Estado do Rio Grande do Sul. Porto Alegre: Base de dados, 2013.

HASENACK, Heinrich; WEBER, Eliseu José. Base Cartográfica Vetorial Contínua do Rio Grande do Sul. Série Geoprocessamento, Porto Alegre: Centro de Ecologia da UFRGS, 2010. 1 DVD.

INSTITUTO BRASILEIRO DE GEOGRAFIA E ESTATÍSTICA. Cidades@ - Município de Rosário do Sul (2010). Disponível em: <http://www.ibge.gov.br.br/>. Acesso em: 25 mai. 2017.

INSTITUTO BRASILEIRO DE GEOGRAFIA E ESTATÍSTICA. Malha municipal do ano de 2010. Disponível em: <http://mapas.ibge.gov.br/bases-e-referenciais/bases-cartograficas/malhas-digitais>. Acesso em: 18 out. 2015. 
INSTITUTO BRASILEIRO DE GEOGRAFIA E ESTATÍSTICA. Dados da produção do ano de 2015. Disponível em: <http://cidades.ibge.gov.br/xtras/perfil.php?lang=\&codmun=431640\&search=| |infogr\%E1ficos:-informa\%E7\%F5es-completas.> Acesso em: 12 dez. 2016.

LINDMANN, Carl Axel Magnus. A vegetação do Rio Grande do Sul (Brasil Austral). Porto Alegre: Livraria Universal de Echenique Irmãos \& Cia, 1906.

MARCHIORI, José Newton Cardoso. Fitogeografia do Rio Grande do Sul: Enfoque histórico e sistemas de classificação. Porto Alegre: EST, 2002.

MARCHIORI, José Newton Cardoso; ALVES, Fabiano da Silva. Campos de areia e silvicultura. Balduinia, Santa Maria, n. 23, p. 01-20, 2007.

MARCHIORI, José Newton Cardoso. Fitogeografia do RS: Campos sulinos. In: CRAWSHAW, Danielle; DALL'AGNOL, Miguel; CORDEIRO, Jão Luís Passos; HASENACK, Heinrich. Caracterização dos Campos sul-riograndenses: uma Perspectiva da Ecologia de Paisagem. Ed. 33. Porto Alegre: Boletim Gaúcho de Geografia, 2004. p. 233-252.

NETTO, Tatiane Almeida. A dinâmica agrária recorrente da soja e da silvicultura na fronteira Livramento/BR e Rivera/UY e seus impactos na agricultura familiar: 2006-2016. 2017. Tese (Doutorado em Geografia) - Universidade Federal de Santa Maria, Santa Maria, 2017.

PEREIRA, Frank Gonçalves. A Expansão da Silvicultura no Bioma Pampa: impactos além dos campos. A sustentabilidade da Região da Campanha - RS: Práticas e teorias a respeito das relações entre ambiente, sociedade, cultura e políticas públicas (2010). Disponível em: <http://w3.ufsm.br/ppgeo/files/ebook02/Artigo\%204.pdf>. Acesso em: 03 dez. 2017.

PICOLLI, Luciana Raquel; SCHNADELBACH, Carla Vilnanova. O Pampa em Disputa: a biodiversidade ameaçada pela expansão das monoculturas de árvores. Porto Alegre: Núcleo Amigos da Terra, 2007.

RAMBO, Balduíno. A fisionomia do Rio Grande do Sul: Ensaio de monografia natural. São Leopoldo: Editora da Unisinos, 1956.

ROSS, Jurandyr Luciano Sanches. Geografia do Brasil. São Paulo: Edusp, 1996.

STRECK, Edemar Valdir; KÄMPF, Nestor; DALMOLIN, Ricardo Simão Diniz; KLANT, Egon. Solos do Rio Grande do Sul. Porto Alegre: EMATER/RS, 2002.

SUERTEGARAY, Dirce Maria Antunes; SILVA, Luís Alberto Pires da. Tchê Pampa: histórias da natureza gaúcha. In: PILLAR, Valério de Patta; MÜLLER, Sandra Cristina; CASTILHOS, Zélia Maria de Souza; JACQUES, Aino Victor Ávila. (Orgs.). Campos sulinos - conservação e uso sustentável da biodiversidade. Brasília: Ministério do Meio Ambiente, 2009. 408 p. p. 42-59.

UNITED STATES GEOLOGICAL SURVEY. Imagens Landsat 5 e Landsat 8. Disponível em: <https://earthexplorer.usgs.gov/>. Acesso em: 29 out. 2016. 